\title{
Source process of the 2007 Niigata-ken Chuetsu-oki earthquake derived from near-fault strong motion data
}

\author{
Shin Aoi $^{1}$, Haruko Sekiguchi ${ }^{2}$, Nobuyuki Morikawa ${ }^{1}$, and Takashi Kunugi ${ }^{1}$ \\ ${ }^{1}$ National Research Institute for Earth Science and Disaster Prevention, 3-1 Tennodai, Tsukuba, Ibaraki 305-0006, Japan \\ ${ }^{2}$ National Institute of Advanced Industrial Science and Technology, Site 7, 1-1-1 Higashi, Tsukuba, Ibaraki 305-8567, Japan
}

(Received December 8, 2007; Revised February 18, 2008; Accepted February 26, 2008; Online published November 18, 2008)

\begin{abstract}
The 2007 Niigata-ken Chuetsu-oki earthquake generated strong ground motions in Kashiwazaki and Kariwa, where the world largest nuclear power plant was in operation. Due to the complexity of the aftershock distribution, activation of the northwest-dipping fault and/or the southeast-dipping fault is proposed. To explore the fault geometry and source process of the earthquake, we performed multi-time window linear waveform inversions for both the fault planes from near-fault strong motion data. A fault plane model of $30 \mathrm{~km}$ in length by $24 \mathrm{~km}$ in width was set to cover the region of aftershock distribution within $24 \mathrm{~h}$ of the mainshock. Both inverted slip models provided moment magnitudes of 6.7 with a small asperity near the rupture starting point, and a large asperity approximately $10 \mathrm{~km}$ southwest of the rupture initiation, which is located in the region of relatively sparse aftershock distribution. Both the small and large asperities are located near the intersection between the two conjugate fault plane models, and the asperities of both models have similar radiation patterns. Therefore, the difference of the residuals between the observed and synthetic waveforms for both models was not significant, indicating that it is difficult to conclude which fault is the rupture.
\end{abstract}

Key words: Source process, waveform inversion, 2007 Niigata-ken Chuetsu-oki earthquake, near-fault strong motion.

\section{Introduction}

The 2007 Niigata-ken Chuetsu-oki earthquake occurred on July 16, 2007, 10:13 JST $(37.557 \mathrm{~N}, 138.608 \mathrm{E}, 17 \mathrm{~km}$ depth, $M_{\mathrm{JMA}}=6.8$; Japan Meteorological Agency, hereafter JMA). The earthquake generated strong ground motions in Kashiwazaki and Kariwa. During this event, K-NET and KiK-net strong-motion networks (Kinoshita, 1998; Aoi et al., 2000, 2004) recorded ground accelerations at 390 and 307 stations, respectively. The maximum peak ground acceleration (PGA) of $813 \mathrm{~cm} / \mathrm{s}^{2}$ was observed at the K-NET Kashiwazaki station (NIG018), and distinct non-linear behavior was identified at the site (e.g., Aoi and Morikawa, 2007; Yoshida et al., 2007). Very strong ground motions were recorded at the foundation slabs (base mats) of all seven reactors of the Kashiwazaki-Kariwa nuclear plant operated by the Tokyo Electric Power Company (TEPCO), which is located on stiff soil with a $V_{s}$ of approximately $500 \mathrm{~m} / \mathrm{s}$. The maximum PGA recorded at the reactor foundation slabs (base mats) was $680 \mathrm{~cm} / \mathrm{s}^{2}$, which exceeds the design level of the nuclear power plant. Two or three pulses are clearly seen in the ground motions at these reactors. Similar pulses were widely observed in the nearfault area, suggesting a complex rupture process consisting of multiple subevents.

The focal mechanism of the earthquake was estimated to be a nearly pure reverse fault with a northeast-southwest

Copyright (c) The Society of Geomagnetism and Earth, Planetary and Space Sciences (SGEPSS); The Seismological Society of Japan; The Volcanological Society of Japan; The Geodetic Society of Japan; The Japanese Society for Planetary Sciences; TERRAPUB. strike direction based on Hi-net (Obara, 2003) and F-net (Fukuyama et al., 1996) analyses (Fig. 1). The aftershock distribution for the earthquake is quite complex, so that rupture on both the SE-dipping fault (e.g., JMA, 2007; Yukutake et al., 2008) and the NW-dipping fault (e.g., Hirata et al., 2007) was proposed. A series of F-net moment tensor analyses indicated that major aftershocks with reverse faulting aligned with the SE-dipping fault (Matsumoto et al., 2007). The Geographical Survey Institute (GSI, 2007) reported that the most plausible source model satisfying geodetic data is a combination of two NW-dipping faults. However, these analyses of the aftershock distribution, moment tensors, and geodetic data have yet to properly clarify the fault plane responsible for the mainshock.

Figure 2 showed that the observed peak ground accelerations (PGAs) and peak ground velocities (PGVs) are consistent with the empirical attenuation relations of $\mathrm{Si}$ and $\mathrm{Mi}$ dorikawa (1999) at fault distances larger than $20 \mathrm{~km}$, independent of which fault plane is assumed. The observed PGAs and PGVs in the near-fault region, on the other hand, were obviously larger than predicted in the case of the SEdipping fault, yet remain in general agreement with the predictions assuming the NW-dipping fault. However, in the near-fault region, the fault distance used in the attenuation relationship becomes more sensitive to the fault geometry, such as the assumed location and size of the fault plane. In addition, the near-fault ground motions are strongly affected by complex source processes and the hanging-wall effect (Abrahamson and Somerville, 1996). Therefore, we cannot uniquely determine which fault plane is appropriate 


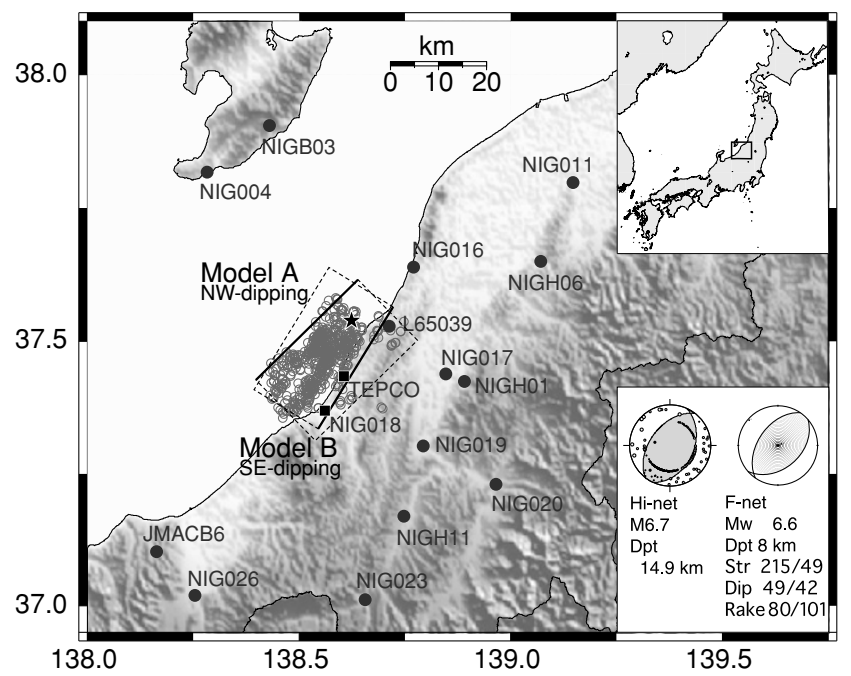

Fig. 1. Distribution of the observation stations used for the inversion analysis (solid circles). Solid squares show stations of the K-NET Kashiwazaki (NIG018) and the Kashiwazaki-Kariwa nuclear power plant (TEPCO). Rectangles show the surface projections of the two fault plane models. Star indicates the epicenter of the mainshock. Open circles denote aftershock locations within $24 \mathrm{~h}$ of the mainshock estimated by Yukutake $e t$ al. (2008), using manual picking of Hi-net data and hypoDD (Waldhauser and Ellsworth, 2000). Focal mechanisms were estimated by the polarity of $P$-wave first motion by Hi-net (left) and the moment tensor analysis of F-net data (right).
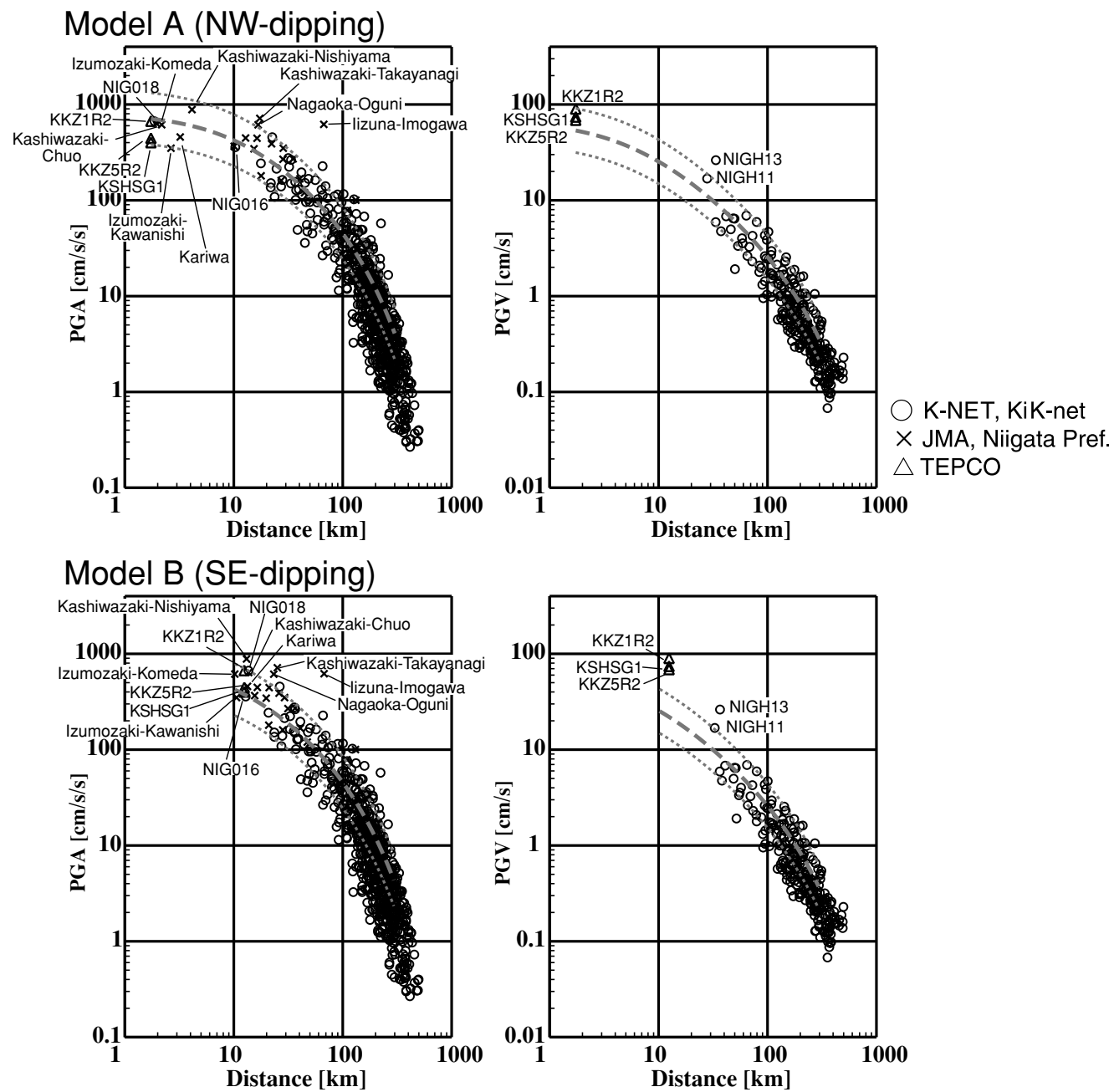

Fig. 2. Comparisons of the observed peak ground accelerations (PGAs; left panels) and peak ground velocities (PGVs; right panels) with the empirical attenuation relations. Upper and lower panels show the cases respectively assuming Model A (NW-dipping fault) and Model B (SE-dipping fault) used in this study. Dashed and dotted lines represent the empirical attenuation relations by Si and Midorikawa (1999) and those standard deviations, respectively. PGVs are converted from the observed velocities on the ground surface into those on a stiff-soil site, where $V_{s}$ is $600 \mathrm{~m} / \mathrm{s}$, following the method of Si and Midorikawa (1999). The number of PGVs is less than that of PGAs because the method requires $V_{s}$ structure of the stiff-soil layer or $30 \mathrm{~m}$ in depth at the site. 

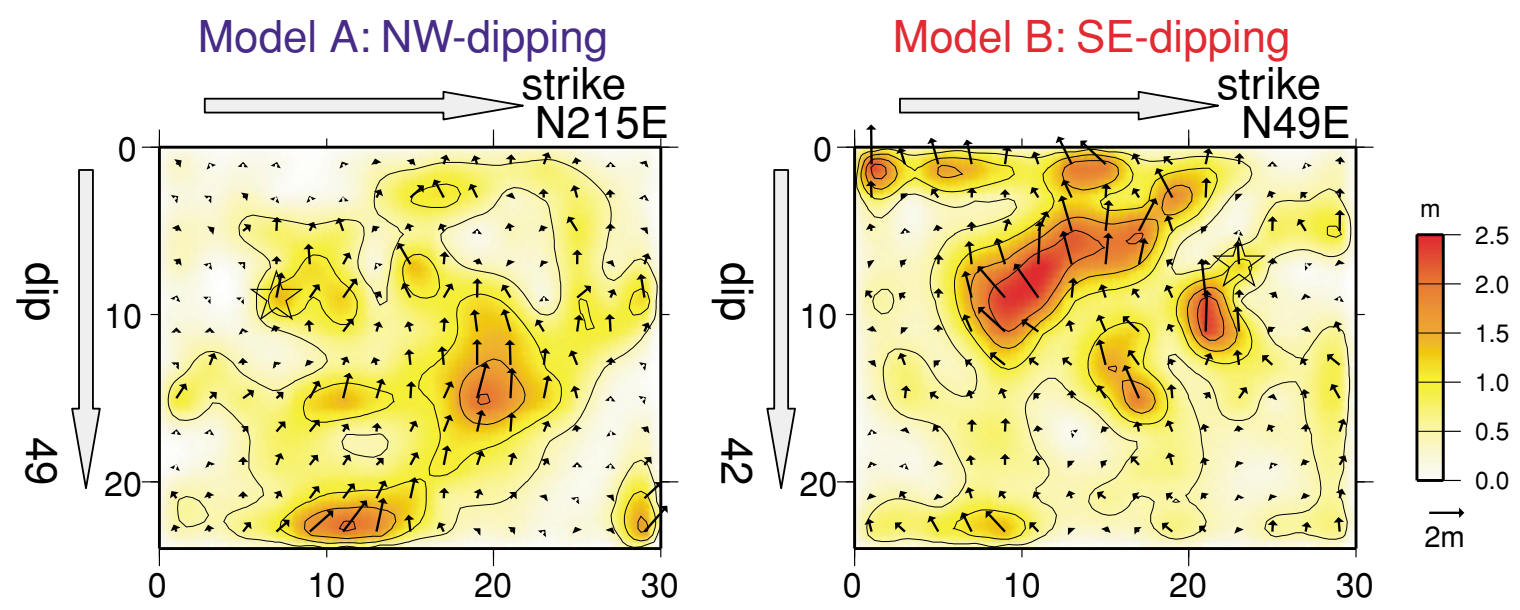

Fig. 3. Estimated total slip distribution for Model A (NW-dipping fault) and Model B (SE-dipping fault). Star indicates the rupture starting point. Arrows show the amplitude and direction of slip.
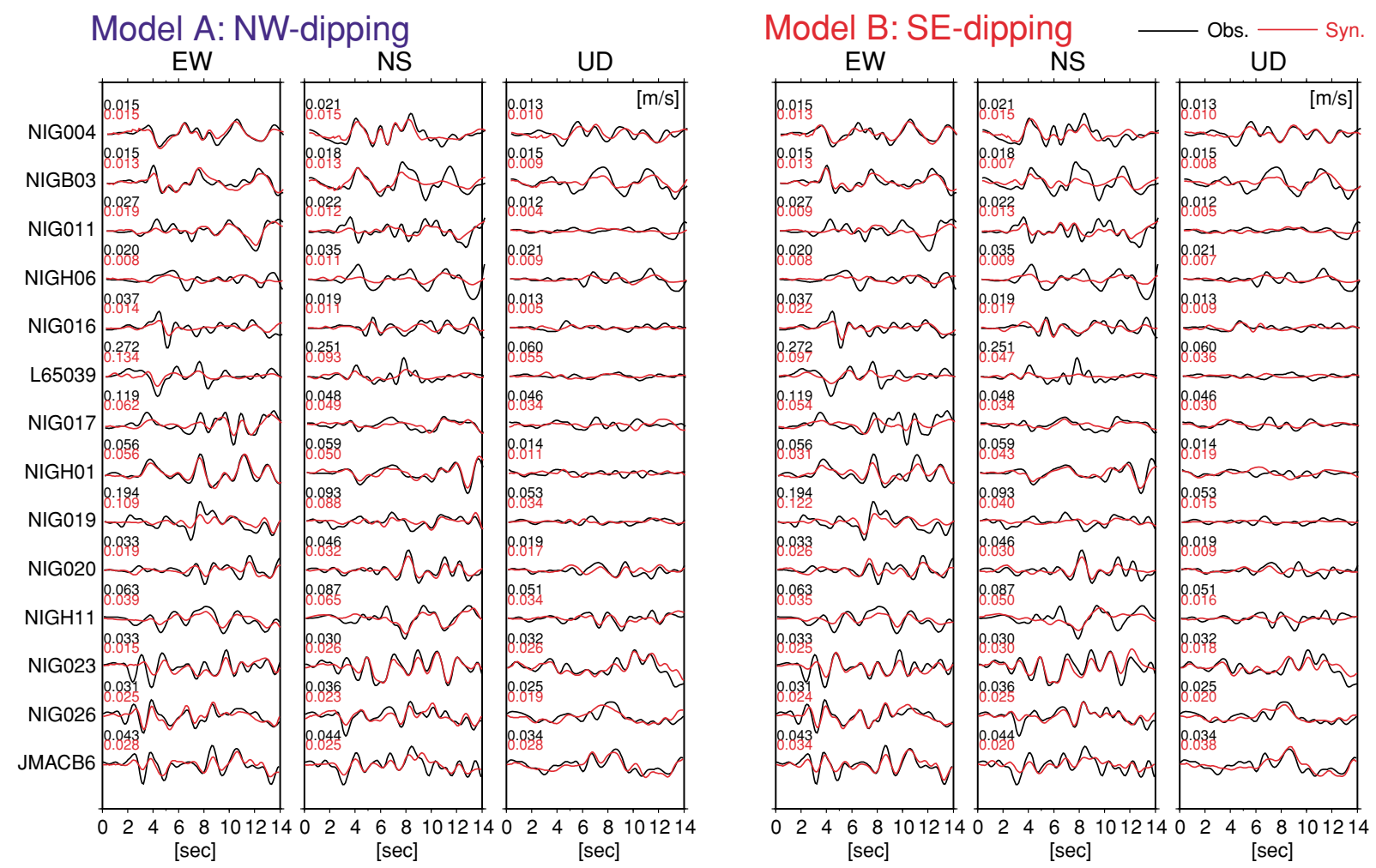

Fig. 4. Comparison between the observed (black) and synthetic (red) velocity waveforms for Model A (NW-dipping fault) and Model B (SE-dipping fault). Maximum values for each component are indicated in the upper-left of each trace in $\mathrm{m} / \mathrm{s}$.

from this examination.

In the present study, we explore the source process that generated strong ground motion in the Kashiwazaki area characterized by the two or three pulsive waves. We also wished to examine the possibility that near-fault strong motion records distinguish the superiority of fault plane geometry among the two possible fault models.

\section{Fault Models and Method of Inversion Analysis}

Figure 1 shows that locations of aftershocks occurring within $24 \mathrm{~h}$ of the mainshock estimated by Yukutake et al. (2008). The hypocenter locations were determined by hypoDD (Waldhauser and Ellsworth, 2000) using manual picking and waveform cross-correlation analysis of Hi-net data. Focal mechanisms were estimated from the polarity of $P$-wave first motion by Hi-net and the moment tensor analysis of F-net data.

As the fault plane for the mainshock has not been clearly determined from the aftershock distribution, we performed waveform inversions for Model A (NW-dipping fault) and Model B (SE-dipping fault). Their strike, dip, and rake angles were set to those of the moment tensor solutions by F-net. The former is N215E, 49, 80 degrees, and the latter is $\mathrm{N} 49 \mathrm{E}, 42,101$ degrees for strike, dip, and rake angles, respectively. The hypocenter determined using Hi-net data was located at 37.54N, 138.61E, and $8.9 \mathrm{~km}$ depth (Yuku- 

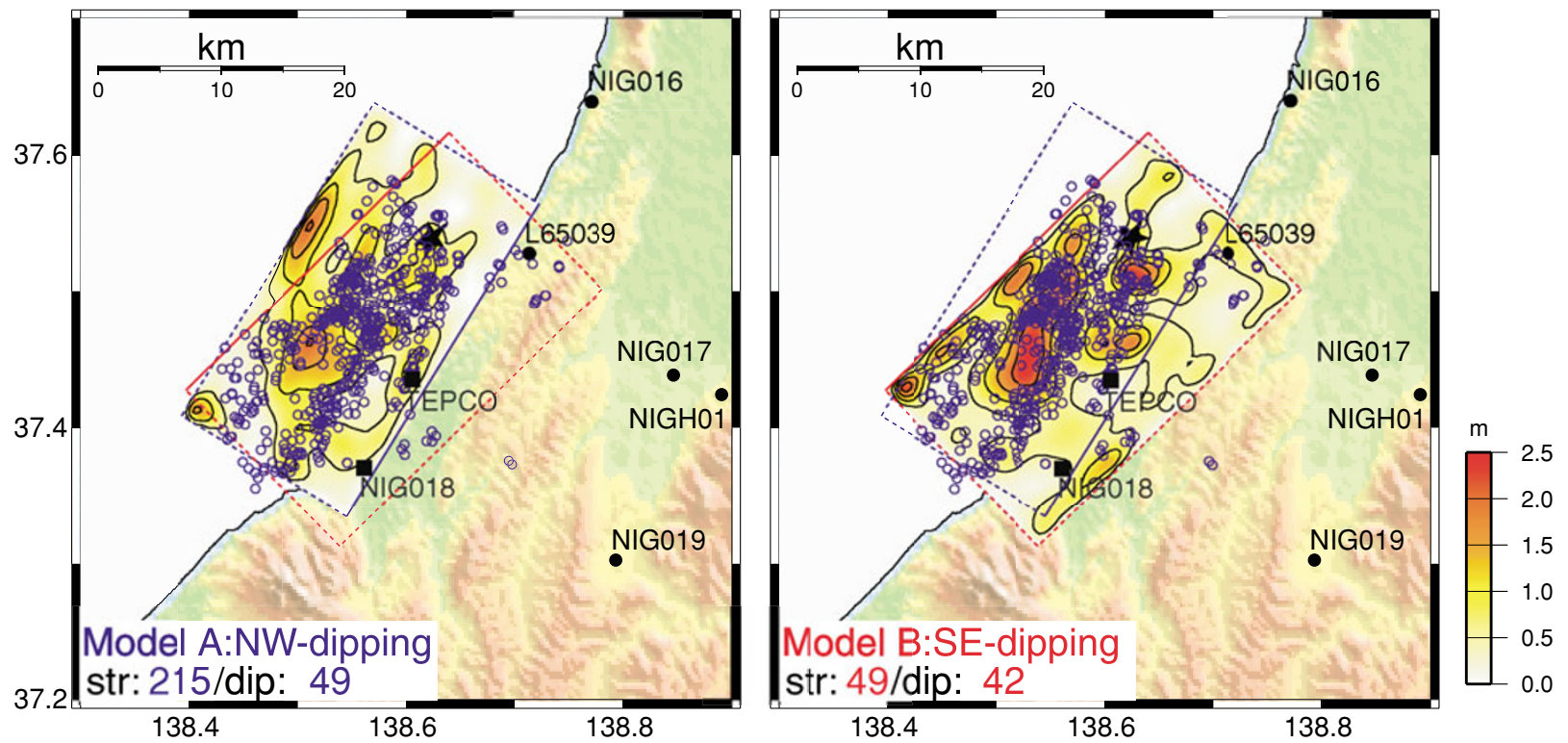

Fig. 5. Projection of inverted slip distribution for Model A (NW-dipping fault) and Model B (SE-dipping fault). Blue circles denote aftershock locations estimated by Yukutake et al. (2008). The large asperities in both the models are located in a region of relatively sparse aftershock distribution.

take et al., 2008). For waveform inversion, we assumed a rupture starting point at the same epicenter and $8 \mathrm{~km}$ depth, and a fault plane model of $30 \mathrm{~km}$ in length by $24 \mathrm{~km}$ in width to cover aftershock distribution within $24 \mathrm{~h}$ of the mainshock.

A multi-time window linear waveform inversion analysis (Hartzell and Heaton, 1983) was applied to estimate the rupture process for both fault planes. We used near-fault strong motion data of 14 stations shown in Fig. 1 from K-NET, KiK-net (downhole), F-net, JMA (JMACB6), and Niigata prefecture (L65039). The observed acceleration records were integrated into velocities, except for F-net velocity data recorded by VSE-355G2, and then bandpass-filtered at $0.1-1.0 \mathrm{~Hz}$. We inverted $14 \mathrm{~s}$ of the $S$-wave portion from $1 \mathrm{~s}$ before the $S$-wave arrivals. As the $S$-wave onset was difficult to identify in most of the observed mainshock waveforms due to the relatively low-amplitude of the initial phase, we estimated these using the $S$ - $P$ times read from the observed waveforms of an aftershock. The differences between the hypocenter locations of the mainshock and the aftershock were corrected using an assumed velocity structure model.

Theoretical Green's functions were calculated using the discrete wavenumber method (Bouchon, 1981) and the R/T matrix method (Kennett and Kerry, 1979) with the different stratified medium for each station. Some of the stations are located on the Niigata plain, which is characterized by sediments of up to $7 \mathrm{~km}$ in thickness. The sediment structures beneath the stations are modeled in reference to $P-S$ logging data provided by NIED, and the results of foundation reflection surveys and foundation drillings conducted by the Ministry of Economy, Trade and Industry (METI). A convolution of moving dislocation was introduced to represent rupture propagation in each subfault (Sekiguchi et al., 2002).

In the multi-time window linear waveform inversion procedure, the moment-release distribution is discretized in both space and time. Discretization in space is performed by dividing the model fault planes into 180 subfaults, each $2 \mathrm{~km}$ by $2 \mathrm{~km}$ in size. Six smoothed ramp functions with a duration of $1 \mathrm{~s}$ separated by $0.5 \mathrm{~s}$ are then applied to represent the slip velocity time function on each subfault.

We solved the least-squared equations to obtain the slip amount of each time window on each subfault to minimize the squared residual of the waveform fit between the observed and synthetic waveforms. To reduce instability or excessive complexity, smoothing constraints were introduced to reduce differences among slips close in space and in time. Non-negative constraints (Lawson and Hanson, 1974) to limit the rake-angle variation were also applied. The rake angles were allowed to vary within plus-minus 45 degrees centered at 80 degrees for Model A and 101 degrees for Model B, corresponding to the rake angles of the moment tensor solutions provided by F-net. Many inversions were performed over various values of triggering velocity for the first time windows and smoothing strength, and the most appropriate values for each were selected based on the residual of the waveform fits and Akaike's Bayesian Information Criterion (ABIC; Akaike, 1980), respectively.

\section{Results and Conclusions}

Figure 3 shows the distribution of slip and Fig. 4 displays the comparison between the observed and synthetic velocity waveforms. Model A (NW-dipping fault plane) has a total seismic moment of $1.42 \times 10^{19} \mathrm{~N} \mathrm{~m}\left(M_{\mathrm{w}}=6.7\right)$. We obtained a large asperity in the southwest deeper part of the rupture starting point, which is close to Kashiwazaki. Model B (SE-dipping fault plane) has a total seismic moment of $1.62 \times 10^{19} \mathrm{~N} \mathrm{~m}\left(M_{\mathrm{w}}=6.7\right)$. We obtained a large asperity in the southwest shallower part of the rupture starting point, which is also close to Kashiwazaki. In both models, we found a small asperity near the rupture starting point and a large asperity approximately $10 \mathrm{~km}$ southwest of the 
rupture starting point, these had a maximum slip of 2.3 and $2.5 \mathrm{~m}$ for Models A and B, respectively. The large asperities fall on to the area with relatively sparse aftershock distribution. The second and third velocity pulses of the observed velocity waveforms seem to be composed of slip from the large asperity. The triggering velocities for the first time windows giving the best waveform fits were $2.5 \mathrm{~km} / \mathrm{s}$ for Model A and $2.1 \mathrm{~km} / \mathrm{s}$ for Model B. As the difference of the residuals between the observed and synthetic waveforms for both the models was not significant, it is difficult to conclude which fault plane more appropriately explains the observations.

As shown in Fig. 5, both the small and large asperities estimated in the inverted source models with the Models A and $\mathrm{B}$ are located near the intersection of the two conjugate fault plane models, which should have similar radiation patterns. Small discrepancies in location, depth, and radiation pattern of the asperities between both the models may be the reason why an assessment of the fault plane dipping is so difficult. Model A, Model B, or a mixture would be considered plausible fault planes for the earthquake. The recently reported aftershock distribution determined using ocean bottom seismometers (e.g., Shinohara $e t$ al., 2008) supports a SE-dipping fault plane. The Earthquake Research Committee (2008) concluded that the major causative fault for the earthquake is a SE-dipping fault plane. In light of the above consensus, our Model B would appear to be the model of choice. Further careful examination of strong motion data and geodetic data will be necessary to clarify the fault orientation and source process of this earthquake.

Acknowledgments. This study was performed using strong motion data of JMA, Niigata prefecture, and TEPCO. The authors thank David Wald and an anonymous reviewer for constructive comments, and Kiyoshi Yomogida for editing.

\section{References}

Abrahamson, N. A. and P. G. Somerville, Effects of the hanging wall and footwall on ground motions recorded during the Northridge earthquake, Bull. Seismol. Soc. Am., 86, S93-S99, 1996.

Akaike, H., Likelihood and the Bayes procedure, in Bayesian statistics, edited by J. M. Bernardo, M. H. DeGroot, and A. F. M. Smith, 143166, University Press, Valencia, Spain, 1980.

Aoi, S. and N. Morikawa, Strong ground motions and rupture process of the 2007 Niigata-ken Chuetsu-oki earthquake, Proceedings of the 35th Symposium of Earthquake Ground Motion, AIJ, 41-46, 2007 (in Japanese with English abstract).

Aoi, S., K. Obara, S. Hori, K. Kasahara, and Y. Okada, New Strong-Motion Observation Network: KiK-net, Eos Trans. AGU, 81, 329, 2000.

Aoi, S., T. Kunugi, and H. Fujiwara, Strong-motion seismograph network operated by NIED: K-NET and KiK-net, J. Jpn. Assoc. Earthq. Eng., 4, 65-74, 2004.

Bouchon, M., A simple method to calculate Green's function for elastic layered media, Bull. Seismol. Soc. Am., 71, 959-971, 1981.
Earthquake Research Committee, Headquarters for Earthquake Research Promotion, Evaluation of the 2007 Niigata-ken Chuetsu-oki earthquake, http://www.jishin.go.jp/main/chousa/08_janchuetsu_oki/index. htm, 2008 (in Japanese).

Fukuyama, E., M. Ishida, S. Hori, S. Sekiguchi, and S. Watada, Broadband seismic observation conducted under the FREESIA Project, Rep. Nat'l. Res. Inst. Earth Sci. Disas. Prev., 57, 23-31, 1996.

Geographical Survey Institute, Crustal deformation and fault model associated with the Niigataken Chuetsu-oki earthquake in 2007 (part 1), Seismol. Soc. Jpn. Programme. Abstr. Fall Meeting, A11-02, 2007 (in Japanese).

Hartzell, S. H. and T. H. Heaton, Inversion of strong ground motion and teleseismic waveform data for the fault rupture history of the 1979 Imperial Valley, California, earthquake, Bull. Seismol. Soc. Am., 73, 1553-1583, 1983.

Hirata, N., H. Sato, S. Sakai, and A. Kato, Source fault of the 2007 Niigataken Chuetsu-oki earthquake, Sci. J. Kagaku, 77, 930-934, 2007 (in Japanese).

Japan Meteorological Agency, Outline of the Niigataken Chuetsu-oki earthquake in 2007, Seismol. Soc. Jpn. Programme. Abstr. Fall Meeting, A11-01, 2007 (in Japanese).

Kennett, B. L. and N. J. Kerry, Seismic waves in a stratified half space, Geophys. J. R. Astr. Soc., 57, 557-583, 1979.

Kinoshita, S., Kyoshin Net (K-NET), Seismol. Res. Lett., 69, 309-332, 1998.

Lawson, C. L. and R. J. Hanson, Solving Least Squares Problems, 340 pp., Prentice-Hall Inc., New Jersey, 1974.

Matsumoto, T., H. Matsubayashi, and T. Kazakami, F-net moment tensor solutions on the Niigataken Chuetsu-oki earthquake, Seismol. Soc. Jpn. Programme. Abstr. Fall Meeting, P1-088, 2007 (in Japanese).

Obara, K., Hi-net: High sensitivity seismograph network, Japan, Lecture Notes in Earth Sciences, 98, 79-88, 2003.

Sekiguchi, H., K. Irikura, and T. Iwata, Source inversion for estimating continuous slip distribution on the fault, - Introduction of Green's functions convolved with a correction function to give moving dislocation effects in subfaults-, Geophys. J. Int., 150, 377-391, 2002.

Shinohara, M., T. Kanazawa, T. Yamada, K. Nakahigashi, S. Sakai, R. Hino, Y. Murai, A. Yamazaki, K. Obana, Y. Ito, K. Iwakiri, R. Miura, Y. Machida, K. Mochizuki, K. Uehira, M. Tahara, A. Kuwano, S. Amamiya, S. Kodaira, T. Takanami, Y. Kaneda, and T. Iwasaki, Precise aftershock distribution of the 2007 Chuetsu-oki Earthquake obtained by using an ocean bottom seismometer network, Earth Planets Space, 60, this issue, 1121-1126, 2008.

$\mathrm{Si}, \mathrm{H}$. and S. Midorikawa, New attenuation relationships for peak ground acceleration and velocity considering effect of fault type and site condition, J. Struct. Constr. Eng., AIJ, 523, 63-70, 1999 (in Japanese with English abstract).

Waldhauser, F. and W. L. Ellsworth, A double-difference earthquake location algorithm: Method and application to the northern Hayward fault, Bull. Seismol. Soc. Am., 90, 1353-1368, 2000.

Yoshida, N., H. Goto, K. Wakamatsu, S. Aoi, S. Fukumoto, and T. Mikami, Investigation on Record at K-NET Kashiwazaki during the 2007 Niigataken-chuetsu-oki earthquake, http://www.civil.tohokugakuin.ac.jp/yoshida/inform/chuetsuoki/k-net-e.pdf, 2007.

Yukutake, Y., T. Takeda, and K. Obara, Well-resolved hypocenter distribution using the double-difference relocation method in the region of the 2007 Chuetsu-oki Earthquake, Earth Planets Space, 60, this issue, 1105-1109, 2008.

S. Aoi (e-mail: aoi@bosai.go.jp), H. Sekiguchi, N. Morikawa, and T. Kunugi 